\title{
A RELIGIÃO CURA?
}

\section{Does religion cure?}

\author{
Wilmar Luiz Barth*
}

\section{RESUMO}

Este capítulo visa demonstrar que, na atualidade, há uma revalorização da religiosidade, da espiritualidade e da religião. Esse fato pode e deve ser avaliado a partir de vários aspectos. É reconhecido que a dimensão espiritual recebe uma atenção e valorização, especialmente por parte da psicologia e da medicina. Isso se torna mais visível quando na relação com a doença e a cura. As religiões (e particularmente a espiritualidade), são importantes aliados neste processo, conforme se noticia e pesquisa. No entanto, observa-se, por conta disso, uma oferta e exploração do religioso e da espiritualidade em favor das chamadas "curas mágicas". As religiões, a medicina e a psicologia devem ter atenção a isso. Existem práticas religiosas que colaboram para a saúde humana.

Palavras-chave: Cura. Religião. Medicina. Psicologia.

\section{ABSTRACT}

This chapter aims to demonstrate that at present there is a revaluation of religiosity, spirituality and religion. Although this fact can and should be evaluated from various aspects, it is recognized that the spiritual dimension receives attention and appreciation, especially from psychology and medicine. This becomes apparent when compared with the disease and healing. Religions and particularly spirituality are important allies in this process, as news and research. However, there is, on that account, an offer and exploitation of religion and spirituality in favor of so-called "magic cures". Religion, medicine and psychology should watch it. There are religious practices that contribute to human health.

Keywords: Healing. Religion. Medicine. Psicology.

* Filósofo e Teólogo. Doutor em Teologia Moral. Professor da Pontifícia Universidade Católica do Rio Grande do Sul. Graduando de Psicologia.

\begin{tabular}{|l|l|l|l|l|l|}
\hline Teocomunicação & Porto Alegre & v. 44 & n. 1 & p. 97-121 & jan.-abr. 2014 \\
\hline
\end{tabular}


"Em nossa prática clínica, observamos que a espiritualidade pode auxiliar as pessoas a enfrentar dificuldades referentes a determinadas experiências de vida e a dar um sentido e uma conotação diferente ao acontecimento mais amadurecido frente aos revezes da vida. O sofrimento não deixa de existir, mas é visto e entendido sob outro ângulo, contribuindo, dessa forma, para o crescimento emocional/existencial do indivíduo"

(MACHADO DA SiLVA e outros, p. 39)

\section{Introdução}

O progresso científico, alavancado pelo racionalismo e o cientificismo que se desenvolveram depois da Idade Média e se firmaram com o renascimento e o iluminismo, trouxe uma série de novos estilos de vida e questões existenciais. A Religião e a Espiritualidade passaram a ser desconsideradas, ocupando uma posição de inferioridade diante dos demais modos de conhecimento. A modernidade tratou de expulsar por completo a presença da religião e da fé e a afirmar cada vez mais as novas tecnologias e o seu método experimental, como sustenta muito bem De Marco (2003). Esperávamos que a ciência respondesse a todos os nossos questionamentos e solucionasse nossos problemas, mas isso não aconteceu. Novas crises e novos problemas expuseram nossa fragilidade humana. Deus foi relegado ao passado, a uma espécie de subproduto, agora obsoleto e ao qual não se poderia recorrer sob hipótese alguma. E a humanidade ficou à deriva de si mesmo.

O sagrado, o religioso e, particularmente, a espiritualidade e a fé retornam como temas de pauta na atualidade. Várias são as causas deste atual fenômeno. Isto é ainda mais visível quando se toma em conta a questão da saúde. Inúmeros são os estudos desenvolvidos nesta área. Muitas pesquisas já oferecem resultados nos quais se demonstra a importância da associação entre saúde e espiritualidade. Muitos insistem na necessidade de aliar a espiritualidade e a fé ao tratamento de saúde e reconhecem a necessidade de considerar a espiritualidade fator importante para o bem-estar do paciente. Esta mudança provocou também uma nova compreensão da saúde, o que fez com que a Organização Mundial da Saúde (OMS), a partir de 1983, modificasse a sua visão com relação à importância da espiritualidade como fator integrante do quadro multifacial da saúde. 
O objetivo deste artigo é colaborar no debate crescente sobre a importância de aliarmos religião, ciência e saúde. Objetiva também apresentar pesquisas, levantar questionamentos ampliadores deste debate e demonstrar que a religião tem um papel preponderante no processo de saúde humano, colaborando, inclusive, com práticas curativas que devem ser afirmadas e ampliadas para uma melhor qualidade de vida. Por fim, o capítulo também deseja questionar a utilização destas práticas genuinamente religiosas em ambientes científicos e demonstrar que o papel da religião não se reduz somente a oferecer "soluções mágicas" e milagres físicos, como se observa em muitos dos novos movimentos religiosos.

\section{O retorno do sagrado e da espiritualidade}

A religião e a espiritualidade eram habitualmente associadas à neurose, à repressão, à imaturidade psicológica, à intolerância, à baixa adesão aos tratamentos médicos e ao baixo nível intelectual. Ambas eram consideradas vestígios do passado e desapareceriam com o avanço científico, como o progresso cultural, social e econômico. O que se observa, no entanto, é o retorno e a difusão da religião e de comunidades espirituais.

Raïssa Cavalcanti (2000) define a sociedade atual como uma "sociedade dessacralizada". No primeiro capítulo de sua obra, ela faz uma longa trajetória identificando fatos e personagens marcantes deste longo processo. Para essa autora, o mundo está fragmentado e é necessário recuperar a visão da totalidade e desenvolver o holismo de modo a superar a visão mecanicista do universo e valorizar a dimensão espiritual. Ela afirma que a recuperação da visão de totalidade pode curar a nossa doença que, segundo ela, são a fragmentação, a dissociação psíquica e espiritual.

Alguns autores, como Enzo Bianchi (2013) e Amatuzzi (2005), definem a sociedade atual com os termos "secularizada" e "desencantada". São termos que se conjugam: secularizada enquanto avessa à religião e desencantada enquanto avessa ao mistério. Este fenômeno caracteriza os séculos XVII a XX. Nesse período, o materialismo, racionalismo e cientificismo reinaram absolutos. Como consequência, resultou uma sociedade fria, calculista e pragmática e isso também tem reflexos nas pessoas e nas relações humanas. 
Este "desencantamento do universo" eliminou qualquer sombra de mistério e magia. A modernidade e pós-modernidade, segundo Barth (2007), mataram ideais e sepultaram tudo o que dizia respeito ao espírito e à espiritualidade. Disto também resultou o reinado do "eu", do individualismo, que fez o homem pregar a si mesmo como senhor absoluto. "Eu sou o meu deus" é a expressão clara desta mentalidade da pessoa nos tempos atuais. No entanto, todo este avanço científico e racional foi como a porta de entrada para novos dilemas existenciais e o ser humano se deu conta de sua fragilidade.

Irrompem agora, por toda parte, novas buscas por respostas a questões e problemas resultantes deste desejo de autonomia plena do ser humano e para completar o que se denominou de "vazio interior". Falase em novos paradigmas. Buscam-se formas existenciais alternativas a tudo o que está aí, o que também afeta profundamente o campo religioso e espiritual. Neste campo, fundam-se novos grupos e comunidades que, embora sem muita clareza, objetivam oferecer aos seus participantes uma experiência mágica de contato com o mistério, a interioridade e o eterno. Novos grupos religiosos se formam para oferecer uma novidade, onde não existem barreiras e onde se oferecem soluções mágicas para todo tipo de problema. Benedetti (2000) fala da "espetacularização do religioso", em que temos a celebração de missas que se assemelham mais a shows, cultos regados à música gospel e durante a qual o participante pode acessar imediata e diretamente o divino.

Este movimento atinge também religiões tradicionais, assombradas por movimentos internos alternativos e que nem sempre são bem vistos e acolhidos. Formam-se comunidades espirituais autônomas que se articulam pelos modernos canais da internet, como verdadeiras redes de espiritualidade não institucionalizadas. Muitos destes grupos oferecem aos seus adeptos verdades absolutas em termos de doutrina, de conduta moral e salvação eterna. Benedetti (2009) afirma que nesses grupos a religião é absorvida e formam-se "religiões de clientela" e onde o sagrado vira objeto de mercado. Além disso, esses grupos garantem a realização de todos os desejos e prometem uma nova vida "aqui e agora", o que leva os fiéis a uma fuga deste mundo como única possibilidade de ação e a negação de tudo o que não está vinculado às suas crenças.

É dentro deste complexo tempo que eclode a dimensão da fé, do místico e do espiritual. É um movimento pela busca da interiorização pessoal e da imersão no mistério. Tudo está articulado e organizado para oferecer aos novos fiéis uma experiência interior de plenitude espiritual, 
de completude, muitas vezes regada à emoção e ao sentimento, à experiência de pertencimento a uma comunidade de iguais e de certezas. E o mais interessante: todas estão abarrotadas de gente. Embora diferentes e até mesmo antagônicas, todas oferecem o mesmo ao seu frequentador: um novo estilo de vida com a garantia de felicidade. Aparentemente todos os frequentadores encontram o que buscam e fazem a experiência plena do êxtase. Se sentem em outra dimensão e totalmente realizados. Mas, será que tudo isso é real ou seria uma forma diferente de plenitude não alcançada na experiência existencial dos séculos passados ou seria resultado do atual estilo de vida e de cultura reinante? O fato é que o vazio existencial, o individualismo, a insegurança, a indiferença e as incertezas marcam a vida pós-moderna e as pessoas acabam buscando alternativas para superar tudo isso. As religiões e as propostas espirituais parecem ser somente mais um modo de enfrentar e superar isso e, o que é pior, podem se tornar verdadeiros balcões de compra e venda, onde o milagre, a cura e a salvação são vendidos.

Observa-se também uma maior importância e interesse no estudo da espiritualidade no meio acadêmico e científico. Cavalcanti (2000) observa que os avanços de muitas disciplinas diminuíram as lacunas que separam a ciência da espiritualidade. Várias Universidades introduziram cursos nos quais se aprofunda esta temática. Fala-se, portanto, de universidades como Massachusetts, George Washington, Duke. Além disso, temos centros como Harvard Medical School e o Mind/Body Medical Institue of Deaconess Hospital em Boston e na Europa o The Spirituality and Psychiatry Special Interest Gruop, do Royal College of Psychiatrists que se dedica ao estudo das interferências entre saúde mental e espiritualidade.

No contexto das práticas de saúde, a influência de aspectos religiosos na cura e no tratamento de doenças tem sido pesquisada por Faria e Seidl (2005) como uma forma de enfrentamento destacada para lidar com situações de adversidade, como a situação de enfermidade. Os autores salientam a importância da escuta dos aspectos religiosos bem como dos demais aspectos do desenvolvimento humano no contexto do atendimento psicológico. ${ }^{1}$

1 CAlvetti, P. U., CAMPIO MÜLler, M., TIEllet NUNES, M. L., Psicologia da Saúde e Psicologia Positiva: Perspectivas e Desafios. Psicologia, Ciência e Profissão, n. 27 , v. 4,2007 , p. 712 . 
A espiritualidade também está em evidência no mundo dos negócios. Como observa Benedetti (2009), práticas espirituais são introduzidas em empresas, de modo a auxiliar os colaboradores a um melhor rendimento do trabalho ou para solucionar dificuldades identificadas nos trabalhadores. Barchifontaine (2007) elenca algumas práticas espirituais importantes e possíveis de serem desenvolvidas no interior das empresas, como a solidariedade, a promoção da dignidade humana, o voluntariado, além da criação de espaços de reflexão, leitura, oração e meditação. A prática mais recorrente é o Yoga, mas também temos notícias de empresas que introduziram monges a fim de orientar práticas de meditação para os funcionários. Mai e Denardin (2005), ao abordarem este tema, afirmam, entre outros aspectos, que a espiritualidade é fundamental nas empresas, pois é a forma mais eficaz de unificar pessoas em torno de um mesmo objetivo, o que é fundamental no mundo dos negócios.

$\mathrm{O}$ interesse pela espiritualidade também se observa na área da psicologia, como afirma Silva Neto (2003): “É espantoso o crescimento nos últimos vinte anos do interesse da Psicologia da Religião e, em particular, pela psicoterapia e aconselhamento religiosos entre profissionais da Psicologia". Este mesmo autor ainda afirma que se multiplicaram os congressos, seminários e, nas Convenções da APA (Associação Psicologia Americana) as sessões que abordam a temática da Religião. A autora Raïssa Cavalcanti (2000) também confirma isso num capítulo de seu livro "O retorno do sagrado na Psicologia". O mesmo pode ser observado no Capítulo de Paulo L. R. Souza e outros. (2004) intitulado: "A religiosidade e suas interfaces com a Medicina, a Psicologia e a Educação: o estado da arte". Neste capítulo os autores afirmam que são agora numerosas as investigações e trabalhos que relacionam estas três áreas do conhecimento.

Algumas revistas e livros também aprofundam esta temática e as pesquisas avançam a passos largos, como o demonstram Guimarães e Avezum (2007) em um levantamento bibliográfico feito por eles. Muitos destes estão elencados na bibliografia que deu origem a este capítulo e muitas outras podem ser acessadas em bibliotecas de universidade ou mesmo online através de plataformas da Internet. Estas pesquisas e estudos são responsáveis pelo aparecimento de novas especialidades como a Psicologia Positiva, a Psicocardiologia e a Psicologia Transpessoal. Mesmo dentro da Psicologia, muitos profissionais já começam a dar importância à temática da espiritualidade e religiosidade. 
Sobre esta temática, indica-se, por exemplo, a obra de Evilázio Borges Teixeira e Marisa Campio Müller, intitulada Espiritualidade e Saúde, lançada em 2012.

As evidências no campo científico que confirmam esse retorno e valorização da espiritualidade são constatadas por uma série de notícias e eventos. Dentre estes destacamos a realização do $\mathrm{X}$ Congresso Brasileiro de Clínica Médica, realizado em 17 de outubro de 2009, que abordou o tema "Espiritualidade na Prática Clínica".

\section{Doenças: castigo de Deus ou mal do corpo?}

A doença sempre afetou o ser humano e sempre foi objeto de investigação, análise e explicações. No passado a doença foi associada a alguma ação dos seres divinos. Conforme Faria (2005), isso aconteceu devido à ignorância dos povos antigos. Em algumas culturas, também a doença era vista como castigo infligido pelo divino em decorrência de alguns comportamentos humanos. Nesses casos, o seu tratamento passou a ser realizado pela religião através de rituais e de indivíduos com poderes especiais para isso. $\mathrm{O}$ xamanismo é uma das práticas mais antigas que compreende esse processo, conforme relata Krippner (2007). Para estes povos antigos, Deus ou os Deuses eram os responsáveis diretos pelas mortes, pelas pestes, catástrofes e males que assolavam o indivíduo e a comunidade. Para obter a libertação de tudo foram estabelecidos ritos, cerimônias e práticas religiosas. Ao realizá-las ou delas participar, o fiel se libertava dos mesmos e alcançava os favores necessários para viver imunizado de tudo.

Nesse contexto se escutam ainda hoje expressões tais como: "Foi vontade divina!", ou "Deus sabe o que faz!" e ainda "Deus não mata, mas castiga!". A cultura popular atual está ainda recheada desta compreensão, fato apontado por Botelho (1991) e Faria (2005). Este último autor acrescenta afirmando que muitas pessoas ainda recorrem a Deus como recurso cognitivo, emocional ou comportamental para enfrentar as doenças.

Nesse caso, a doença não é vista como algo da pessoa e de um estilo de vida ou como algo natural, mas uma realidade a ser temida, como um inimigo a ser vencido. Embora as religiões possam ter se beneficiado disto e muitas ainda estejam explorando este comportamento, esta prática inibe o comportamento religioso autêntico e impede a ligação do ser humano com o transcendente. Instaura uma infantilização da fé e da 
prática religiosa que, no fundo, cria uma clientela de fiéis e não pessoas maduras e de fé autêntica. Bernie Siegel (1989), em seu livro Amor, Medicina e Milagres, reconhece que os médicos também continuam procedendo como se fosse a doença que ataca as pessoas, em vez de compreender que as pessoas é que contraem a doença, por se tornarem suscetíveis a sua causa, à qual todos nós sempre estamos expostos. Esta compreensão inadequada da doença e de suas causas atrapalha uma melhor compreensão da mesma e que precisa também ser modificada pelas religiões e pelas ciências da saúde.

Ficou evidente que existe um entrelaçamento entre comportamentos, ritmo de vida e doença. Os estilos de vida ditam as doenças que teremos ou já temos. Pessoas que fumam ou bebem têm uma propensão a adoecer ou têm a propensão a desenvolver um tipo particular de doença em decorrência deste hábito. Popularmente as pessoas já sabem disto: "Desse jeito vai acabar desenvolvendo um câncer!" ou, "Depois da morte do filho, ela perdeu o sentido da vida e se entregou à doença!". A poluição do ar gera doenças e os estilos de vida também. Os profissionais da saúde não se cansam de estabelecer este nexo para os seus pacientes. Por que a vida frenética ou as preocupações em excesso não provocariam o estresse e a depressão?

É fácil jogar a culpa da doença em Deus. Desse modo, não modificamos práticas e hábitos que não são saudáveis e obrigamos os deuses e a religião a intervirem em nosso favor quando, no fundo, não é essa sua verdadeira tarefa.

Ainda temos dificuldade de associar estilos de vida e comportamentos com doenças. Como afirmam Machado da Silva e outros (2012), baseando-se em autores como Serafino, Kaptein e Weinman, "com o avanço da Medicina Comportamental e da Psicossomática, passamos a perceber que os comportamentos e as crenças humanas estavam também implicados na saúde, dando início, na década de 1970, à Psicologia da Saúde". Para este autor, é fundamental recuperar o paradigma biopsicossocial espiritual.

As pesquisas mostram que alguns povos têm uma propensão alta a algumas doenças e trazem em seu genótipo esta "falha". Assim como especifica Siegel:

Para quem está de fora, a ligação pode parecer artificial, mas só o doente saberá ajuizar se ela existe ou não. Como já vi o nexo acontecer muitas vezes, cheguei à conclusão de que sensibilizamos 
os órgãos do corpo mediante uma forma de realimentação biológica negativa. $^{2}$

Tivemos uma mudança bastante importante feita pela medicina e a psicologia, ou seja, passamos a estudar pessoas que não adoecem. Um caso, neste particular, foi o da cidade de Veranópolis, no Rio Grande do Sul. No levantamento populacional, percebeu-se que nesta cidade as pessoas viviam mais e ela foi batizada como a "cidade da longevidade", um chavão interessante logo adotado pelo poder público local para atrair turistas e assim incrementar a economia local. Seguiram-se então diversos estudos tentando identificar as causas deste fenômeno e os resultados foram diversos como o consumo de vinho, a qualidade do ar e a qualidade da alimentação. Outro caso interessante, e mais particular ainda, diz respeito a um familiar que durante muitos anos definia-se como "doente" e se tratou com diversos médicos, posteriormente com curandeiros, cartomantes e adivinhos, chegando inclusive a entrar em atrito com sua comunidade religiosa local e toda a vizinhança. Tal pessoa tornara-se insuportável e era evitada, até que morreu seu companheiro. Passado um período de aparente luto pela perda, esta pessoa gradativamente vai retomando sua vida e atividades e o comportamento, reatando laços sem mais assumir o papel de doente. Ficou claro para ela e para os mais próximos que o verdadeiro motivo de sua doença era uma relação familiar conturbada. A válvula de escape eram as doenças.

Creio que existem dentro de nós mecanismos biológicos de 'vida' e de 'morte'. A pesquisa científica de outros médicos e a minha própria experiência clínica diária convenceram-me de que o estado de espírito altera o estado físico, agindo por meio do sistema nervoso central, do sistema endócrino e do sistema imunológico. ${ }^{3}$

Reduzir as doenças ao âmbito puramente biológico deixou de ser uma tese defendida atualmente, como observa Helman (1994). Podemos afirmar ainda mais: a própria morte não é um fator que pode ser visto somente sob o aspecto biológico. São inúmeras as pessoas que se entregam à morte como única forma de solucionar um problema

2 SIEGEL, Bernie S., Amor, medicina e milagres. Porto Alegre, Editora Best Seller, 1989, p. 119.

3 SIEGEL, Bernie S., idem, p. 12. 
pessoal ou social, como se observa nos suicídios tanto individuais quanto coletivos. Mas não somente nestes casos.

Neste caso, o papel das religiões e a "ajuda divina" são muito mais eficazes no nível dos estilos comportamentais, na busca e intervenção nos problemas concretos das pessoas e comunidades, do que em "milagres" e "soluções mágicas" vindas do alto. Aliás, muitas religiões, sobretudo no Brasil, criaram e mantêm atividades de cunho pastoral voltadas para isso, como podemos lembrar a Pastoral da Criança e a Pastoral dos Doentes. São ações que demonstram mais eficácia do que os milagres prometidos.

\section{A medicina, a doença e a morte entre nós}

Ficar doente ou estar doente sempre foi e será um drama humano. Apesar do aumento expressivo de hospitais, médicos, tratamentos e pesquisas, esse drama se mantém inalterável. Ou seja, o conhecimento e as melhorias sociais não conseguiram amenizar o impacto desta questão.

A doença e a morte são os novos tabus em substituição ao sexo e o prazer físico do passado os quais eram vistos e tratados como pecado. Sobre esses temas não se fala e não se pensa e se elaboram planos de fuga, embora a imprensa diariamente apresente os números de mortos e feridos e os jogos eletrônicos explorem a violência e a eliminação dos adversários e brindem o ganhador com novas vidas.

Estamos como que anestesiados diante da doença e da morte. Nas faculdades ligadas à saúde, constatou-se que os profissionais formados sabem lidar muito pouco com a morte e dialogar com os pacientes sobre isso. Muitas estratégias e desculpas são apresentadas para evitar qualquer diálogo do profissional com o paciente. Instalam-se jogos de esconde-esconde e o paciente fica à mercê de alguma informação sobre seu quadro de saúde que consegue somente interrogando os mais próximos. Em muitos casos, o próprio paciente aceita este silêncio para evitar os constrangimentos de familiares e profissionais. Faz-se tudo, menos falar sobre doença e morte. Nas cerimônias religiosas, as frases mais ouvidas são: "Foi melhor assim, ao menos ele não sofreu!"; "Os médicos fizeram tudo o que podiam e nada mais poderia ser feito!" ou "Deus sabe o que faz!".

O que temos hoje é a incapacidade de aceitar a doença no contexto de uma sociedade de "corpos perfeitos". A vida foi medicada. As farmácias e as academias estéticas se espalham por todas as esquinas. 
Temos que parecer todos belos e bonitos. Temos que parecer todos perfeitos e saudáveis, o que é um indicativo de doença espiritual. Temos uma comercialização da doença e a indústria de tratamentos, remédios, clínicas, planos de saúde. Negamos a doença e, quando ela aparece, nasce um sentimento de culpa e revolta que recai sobre o próprio doente. A morte, nos casos mais extremos, é uma saída desejada e por isso mesmo a sua antecipação pelo sujeito é uma forma às avessas de vencê-la.

A falha da empatia é que produz a desconsideração pela pessoa, que fica reduzida a mero número ou objeto, observado à distância $\mathrm{e}$ sem possibilidade de contato com o que está sentindo, como quando lemos uma notícia no jornal sobre catástrofes, mortes, genocídios e continuamos tranquilamente sorvendo nosso café. ${ }^{4}$

Para alargar este quadro, é importante lembrar que vivemos uma crise da instituição médica e uma invasão de novas medicinas, denominadas "alternativas", como afirmam Tesser e Luz (2002). A chamada biomedicina se tornou mecanizada e desumana e obscurece a visão global do doente e da sua doença. Seria ela uma forma de revolta popular contra a medicina oficial? A vulnerabilidade da pessoa no atual contexto social e médico obrigam muitos a desistirem até mesmo de lutar para viver.

Torna-se claro na prática clínica que, na grande maioria das vezes, não é possível fragmentar o paciente em várias partes como social, biológica, psíquica e espiritual, afinal todas são interligadas e podem ser responsáveis pelas comorbidades, aderência aos medicamentos, sucesso e fracasso no tratamento. ${ }^{5}$

Por fim, temos que reconhecer que os doentes são vistos e tratados como um verdadeiro peso social, familiar e econômico. $\mathrm{O}$ custo do doente e de seu tratamento é extremamente alto e desgastante para qualquer família e Estado. $\mathrm{O}$ doente também se sente um incômodo para todos. Não sabemos como lidar e o que fazer com o doente.

4 DE MARCO, M. A. Medicina: tecnologiae/ou humanismo? In: CATALDO NETO, A.; ANTONELLO, I.; ITAQUI LOPES, M. H. O estudante de medicina e o paciente: uma aproximação à prática médica. Porto Alegre, EDIPUCRS, 2007, p. 87.

5 LUCCHETTI, G. et al. Espiritualidade na prática clínica: o que o clínico deve saber? Revista Brasileira de Clínica Medica, v. 8, n. 2, 2010, p. 155. 
Não temos sequer espaço para ele, muito menos tempo para ficar ao seu lado. Ou seja, tudo o que mais evitamos é não passar jamais por essa situação. Esse quadro não ajuda e, o que é pior, dificulta ainda mais uma mudança de perspectiva.

\section{Religião, religiosidade e espiritualidade}

Espiritualidade, religião e religiosidade são termos próximos que se fundem, mas também são confundidos e tomados como sinônimos. Torna-se necessário reconhecer uma distinção. Isso permitirá levantar algumas preocupações que se impõem a todos os que lidam com a religião e a saúde. Afinal, o que pode ser enquadrado como espiritualidade? A espiritualidade é submissa à religião e, portanto, somente pode ser administrada por ela? As práticas religiosas das pessoas são de domínio da Religião e, portanto, outras pessoas não podem se ocupar delas?

Começamos por uma definição e compreensão dos termos e seu campo específico. A espiritualidade está ligada à busca do sentido último da vida e ao encontro de uma razão existencial para viver. Teixeira (2010) afirma que a espiritualidade não é algo que ocorre para além da esfera do humano, mas algo que toca em profundidade sua vida e experiência. Vigil (2005) afirma que a espiritualidade aparece hoje como uma dimensão essencial do ser humano, que o distingue, uma força ligada ao sentido da vida e da sua evolução. Conforme Ferrer (2002), toda pessoa é necessariamente espiritual, pois é dotada de um espírito.

A palavra espírito não compreende necessariamente a existência de um Deus, mas a presença da autoconsciência na pessoa, ou seja, a capacidade de reflexão e transcendência inerentes a todo ser humano. Assim, a espiritualidade compreende a busca de si mesmo, da sua realidade existencial mais profunda. Para isso utilizam-se técnicas variadas que não são obrigatoriamente de origem religiosa.

Quanto à espiritualidade, Luccheti e outros (2009) consideram-na como uma busca pessoal para entender questões relacionadas ao fim da vida, ao seu sentido, sobre as relações com o sagrado ou transcendente que, pode ou não levar ao desenvolvimento de práticas religiosas ou formações de comunidades religiosas. Guimarães e Avezum (2007), apoiados em Saad (2001) e Volcan (2003), definem espiritualidade como a propensão humana a buscar significado para a vida por meio de conceitos que transcendem o tangível: um sentido de conexão com algo maior que si próprio, que pode ou não incluir uma participação 
religiosa formal. Giovanetti (2005) afirma que espiritualidade designa toda vivência que pode produzir mudança profunda no interior do homem e o leva à integração pessoal e à integração com outros homens.

A espiritualidade pode estar ligada à religião, mas não necessariamente, afirma Ferrer (2002). Aliás, nas últimas décadas, inúmeras técnicas de origem oriental afloraram no ocidente exatamente porque ajudaram as pessoas a encontrarem a si mesmas. Embora tenham uma origem religiosa, entre nós não assumem essa conotação. Entre os principais motivos disto, está o fato de a cultura ocidental ser extremamente voltada para o exterior. Entre nós valorizam-se as relações sociais, o pragmatismo e o ativismo. Entre as principais técnicas que viraram moda está o Yoga. Inicialmente as religiões ocidentais, como o cristianismo, perseguiram esta prática por achar que seria uma forma de o Hinduísmo e Budismo se espalharem no ocidente, mas logo se percebeu que o interesse estava ligado a uma busca de interiorização, de autoconhecimento e autocontrole e que seus adeptos não desejavam importar uma religião, mas beneficiar-se de uma de suas práticas. Hoje temos grupos praticantes do Yoga em praças e centros sociais sem qualquer vínculo com sua origem religiosa.

Conforme Saad (2008), espiritualidade seria um conjunto de crenças que trazem vitalidade e significado aos eventos da vida, uma propensão humana para o interesse pelos outros e por si mesmo, atendendo a uma necessidade de encontrar razão e esperança e vontade para viver. A espiritualidade, continua o autor, é uma fonte de conforto, bem-estar, segurança, significado, ideal e força.

Lucchetti e outros (2009) definem religião como um sistema organizado de crenças, práticas, rituais e símbolos designados para facilitar o acesso ao sagrado, ao transcendente (Deus, força maior, verdade suprema). Koenig (2001) define-a como um sistema organizado de crenças, práticas, rituais e símbolos projetados para auxiliar a proximidade do indivíduo com o sagrado e/ou transcendente. Nesse caso, a religião nasce como instituição que visa colaborar com a pessoa para que esta possa atingir sua plenitude existencial, sua realização humana plena. Essa plenitude recebe nomes diferentes como Paraíso, Nirvana, Perfeição, Moksa ou Tao e tantos outros. A religião tem uma tarefa muito séria e profunda. Somente ela pode dar ao homem o verdadeiro sentido da vida e projetá-lo para o alto, para além de si mesmo, para o Transcendente. Ora, uma pessoa que perde essa condição, acaba perdendo o que tem de mais profundo, de mais sólido e, como 
sabemos, quando falta a base existencial, a vida humana se torna uma fonte inesgotável de problemas. Nesses momentos a doença física é somente uma forma dessa manifestação.

Se observarmos atentamente toda atividade desenvolvida pela religião, perceberemos que sua missão consiste em dar esta esperança, criar esta rede de apoio, estabelecer mecanismos que permitam à pessoa acessar seu interior libertando-se de ressentimentos, de falsas seguranças.

Da mesma maneira como se fala em religião, faz-se necessário definir religiosidade. Tanto uma quanto outra está presente na história da humanidade, embora a religiosidade seja anterior à religião. Por religiosidade, conforme Luccheti e outros (2009), compreende-se o quanto um indivíduo acredita, segue, pratica uma religião, o que pode ser feito de modo organizado ou não. Neste caso, temos pessoas que frequentam regularmente o espaço sagrado religioso como também temos pessoas que se limitam a acessar conteúdos e práticas devocionais de modo bastante aleatório. Hoje temos muitas pessoas com religiosidade, mas sem religião.

Percebe-se, portanto, uma clara distinção entre os três termos. Quando se aborda religião, religiosidade, espiritualidade, não se fala das mesmas coisas, elas não são sinônimos. Portanto, muitas pessoas que estudam este tema não têm sempre a pretensão de estudar religião, mas espiritualidade. Temos que considerar que hoje muitas pessoas se interessam por espiritualidade e não por religiosidade ou religião, o que é um fenômeno bem pós-moderno. A inexistência de uma cultura de relação e vínculos e a aversão moderna a todas as formas de institucionalização forçam muitas pessoas a buscar a espiritualidade sem vínculos a uma prática religiosa especifica. Ao mesmo tempo, por espiritualidade podese perceber um universo difuso de práticas que pode consistir tanto em ler um livro de autoajuda sob um guarda-sol na beira da praia como a recitação do rosário católico em uma igreja ou ainda a captação da energia cósmica em algum local específico estabelecido.

\section{O que dizem as pesquisas e os números?}

Antes renegados ao segundo plano, os cursos de espiritualidade passaram a ser vinculados na maioria das universidades norteamericanas. Em 1993, menos de cinco escolas médicas dos Estados Unidos possuíam a disciplina de religião/espiritualidade 
em Medicina, valor que subiu para mais de 100 nos últimos 15 anos. Seguindo esta tendência, 59\% das escolas médicas britânicas já possuem cursos relacionados à espiritualidade. ${ }^{6}$

Ao analisar as atuais publicações científicas sobre o tema Religião, Espiritualidade e Saúde, chegamos a números convincentes que possibilitam afirmar tratar-se de uma verdadeira expansão dos estudos nesta área. Crossley e Salter (2005) demonstram esta expansão através do levantamento de dados, assim como Guimarães e Avezum (2007). Lucchetti e outros (2010) também fizeram este levantamento, confirmando serem numerosas as pesquisas científicas e o aumento dos estudos nesta área e a consequente expansão da discussão desta temática em revistas de renome internacional e em centros universitários no mundo. Temos estudos vinculando espiritualidade e religiosidade a doenças como a depressão, a ansiedade, a melhor qualidade de vida, ao aumento da imunidade, a menores índices de consumo de drogas lícitas e ilícitas e, por fim, ao vínculo com as doenças mentais, todas demonstrando a conexão entre religião e espiritualidade com a saúde.

No Brasil também tem avançado o estudo e a pesquisa nesta área. Dalgalarrondo (2007) faz um levantamento histórico sobre estudos vinculando religião e saúde mental. Segundo ele, a presença do religioso no modo de construir e vivenciar o sofrimento mental tem sido observado por muitos pesquisadores.

$\mathrm{Na}$ Universidade de Manchester, desenvolveu-se um estudo e se descobriu que pessoas que meditam regularmente suportam melhor a dor, pois o método treina o cérebro para focar no presente. "A meditação se tornou um caminho complementar no tratamento de dor crônica!", afirma Christopher Brown, o pesquisador responsável (Jornal O Globo, 14/05/2011). Observou-se também que atividades e crenças religiosas estão relacionadas à melhor saúde e qualidade de vida, conforme pesquisa veiculada por Koenig (2001). Os doentes gostariam que seus médicos falassem com eles sobre religião e espiritualidade, conforme pesquisa veiculada por Mc Cord e outros (2004).

Centenas de estudos têm investigado a relação entre o envolvimento religioso e saúde mental. A maioria deles revela que, quanto maior o envolvimento religioso, maior o bem-estar e a saúde mental. O uso

${ }_{6}$ LUCCHETTI, G. et al. Espiritualidade na prática clínica: o que o clínico deve saber? Revista Brasileira de Clínica Medica, v. 8, n. 2, 2010, p. 156. 
positivo da religião esteve associado não só a melhores resultados físicos e mentais em pacientes com enfermidades graves, como também entre as vítimas de traumas psicológicos, por exemplo, pessoas afetadas por catástrofes naturais. ${ }^{7}$

Um estudo realizado por Inzlicht (2011) traz evidências que apontam para o fato de pessoas que têm mais fé sofrerem menos de estresse. A fé consegue fazer o cérebro reagir de maneira diferente frente aos problemas e isso pode ser sentido em todo o corpo, proporcionando mais saúde e um bem-estar geral. A pesquisa confirmou que a firme convicção em algo faz com que o cérebro aumente a produção de células de defesa do corpo e há também uma série de alterações benéficas no sistema hormonal.

Ao contrário do que se imaginava no passado, Gail Ironson e outros (2002) comprovaram que pessoas com espiritualidade têm mais resiliência e aderem melhor ao tratamento médico. Vários estudos sobre esta questão foram desenvolvidos e as conclusões são as mesmas. Estas pesquisas derrubam uma antiga ideia de que as pessoas que desenvolvem práticas religiosas aceitam passivamente a chamada "vontade divina". A pessoa com fé desenvolve valores como a esperança e a confiança. Ela acredita que não será desamparada no momento da dificuldade e passa a confiar que seu Deus a salvará e libertará da doença e, desde modo, aumenta sua capacidade de entrega ao tratamento e procedimentos invasivos, tendo períodos menores de recuperação em hospitais. Ela confia no médico porque reconhece nele e nos esforços da medicina a vontade divina. Junto com isso, ela desenvolve o valor da confiança e da persistência.

Pessoas que frequentam uma religião e/ou têm espiritualidade apresentam também menores índices de consumo de drogas e apresentam melhores índices de recuperação nestes casos, conforme demonstraram Zila Sanchez e Solange Nappo (2007). Inúmeras são as clínicas e fazendas de recuperação de pessoas com dependência química, mantidas por grupos religiosos. Embora possamos discutir os métodos empregados, sabe-se que a sua busca e eficácia é altíssima e gozam de boa fama entre nós.

7 PERES, J. F. P.; SIMÃO, M. J. P.; NASELlO, A. G. Espiritualidade, religiosidade e psicoterapia. Revista de Psiquiatria Clínica, v. 34, supl. 1, 2007, p. 138. 


\section{Práticas espirituais/religiosas e seus benefícios à saúde}

A visão de alguns expoentes da área da psicologia sobre a espiritualidade/religiosidade não era muito positiva no passado. Charcot definia-a como uma patologia. Freud, em sua obra $O$ mal estar da civilização, de 1930, compreendia-a como uma distorção da vida real e como um delírio. Ao lado destes temos psicanalistas importantes como Carl Gustav Jung que desenvolvia uma postura bastante positiva da espiritualidade.

Não é pretensão afirmar que as religiões exercem um efeito positivo na vida das pessoas, embora alguns leitores se oponham a isso. As religiões convocam as pessoas a buscarem algo a mais, um além, um sentido pleno para a existência. Sabe-se muito bem que uma pessoa que tem objetivo e propósito positivos em sua vida tende a ser mais constante e comprometida em sua existência. Ao mesmo tempo, as religiões apontam para seus fiéis algumas pessoas que são exemplos positivos, ícones de espiritualidade e de ações comprometidas em prol de uma vida integral, o que pode contribuir para gerar nos fiéis as mesmas ações. Além disso, as religiões impõem a seus adeptos práticas saudáveis como o não uso de drogas, bebidas, o cultivo interior, práticas de solidariedade e o comprometimento com ações sociais e de transformação da realidade. As religiões geram sentimento de esperança, de altruísmo, de não estar só e a certeza de que toda realidade pode ser transformada. Estas ações colaboram para a melhor qualidade de vida e, sobretudo, são fonte de cura e enfrentamento das dificuldades.

Além disso, vale lembrar que muitos hospitais e ações pastorais são mantidos pelas religiões. Nesses espaços, a medicina e a espiritualidade andam juntas e são desenvolvidas inúmeras pesquisas na área médica. Isso permite dizer que as religiões, ao menos na sua maioria, não se opõem às práticas médicas e, inclusive, as mantêm e promovem. Nas atividades promovidas pelas religiões, podem ser destacadas palestras de formação em diversas áreas e os grupos servem como apoio para os integrantes, um espaço onde reforçam laços de amizade e aprofundam sua fé.

É preciso também considerar que a espiritualidade pode exercer efeitos negativos sobre a saúde. Isso pode ser observado em construções mentais de pessoas doentes. As interpretações distorcidas sobre a origem e causas de sua doença pode levá-las a desenvolver sentimentos de culpa, repressão, autoestima baixa, ansiedade e medo e, neste caso, a aceitar e 
resignar-se diante da doença. Esses pensamentos podem levar a pessoa a assumir uma posição de passividade e submissão a qualquer realidade, a não empenhar-se em superar dificuldades e, sobretudo, a resignar-se. A resignação e a falta de perspectivas são a porta de entrada para todo tipo de doença e isso deve ser combatido pelas religiões.

Por outro lado, Saad (2008) enumera cinco possíveis explicações de como a religião pode afetar a saúde: respeito ao corpo; melhor estado psicológico, pois gera esperança, perdão, altruísmo e amor; otimização de vias psiconeuroimunológicas, psiconeuroendócrinas e psicofisiológicas; melhor estratégia do lidar e redução do estresse; aos pacientes com câncer, a prática da prece correlacionou-se significantemente com a escala de saúde geral e de funcionalidade.

Uma prática possível de ser observada é a introdução de práticas regulares religiosas em sessões de terapia e na base de formação de grupos, como descreve Silva Neto (2003). Segundo o autor, duas técnicas importadas de tradições religiosas formais como a meditação e o perdão são usadas como complemento ao aconselhamento terapêutico; e técnicas tradicionais de aconselhamento são adaptadas a clientes religiosos. Silva Neto ainda sugere outra mudança paradigmática importante a ser aplicada na psicologia, ou seja, olhar os fenômenos psíquicos de um ponto de vista religioso, contrário ao hábito de olhar os fenômenos religiosos reduzindo-os a manifestações psíquicas.

Como primeira prática religiosa, aponto a oração, a prece diária e a prece intercessora. Rezar ou orar é uma forma humana de entrar em contato com o divino, uma forma de conexão, uma prática humana semelhante à conversa que temos com aquele com o qual nos vinculamos. Ora, quando não mantemos esta ligação com os outros, o tempo se encarrega de enfraquecer estes laços e eles desaparecem. A oração tem a finalidade de vincular a criatura ao seu criador. Mas não só. Rezar também é uma forma de entrega total a um Outro (Deus, Absoluto, Ser Supremo). É a abertura ao Outro. Quem reza se confia ao grande Outro e tem a plena certeza de não ficar desamparado. Ora, esta atitude é importante para a pessoa e o sucesso de um tratamento médico também depende deste sentimento. O paciente precisa acreditar e colaborar, seja no remédio ou no seu médico e precisa fazer a experiência da entrega, da confiança. Este ingrediente no tratamento contribui para seu sucesso.

Guimarães e Avezum (2007) apresentam os estudos feitos por alguns pesquisadores sobre a importância da prece intercessora em pacientes e concluíram ser ainda insuficiente estabelecer evidências da 
influência na saúde. Esta prática, bastante simples, consiste em solicitar ao divino através da oração a saúde de pessoas doentes. Existem várias práticas populares como correntes de pensamento, a "torcida" pela vitória e o pensamento positivo que são utilizadas por pessoas quando se encontram em dificuldades.

Da oração podemos passar para a contemplação. Por contemplação compreendo esta capacidade de "olhar para além de si mesmo" e, ao mesmo tempo, "para o mais íntimo de si mesmo". A contemplação permite-nos "olhar o todo" e, sobretudo, enxergar-se nele, perceberse imerso nele. A contemplação retira-nos de nós mesmos e joga-nos, projeta-nos para além do tempo e do espaço. A contemplação permite fazer a experiência de "olhar de fora", do alto, a nós mesmos e o nosso contexto. Muitas religiões desenvolvem esta ação. Esta capacidade é fundamental para poder abstrair da realidade e perceber-nos como uma unidade e não presos à pura materialidade, permitindo sentir-nos mais e, além de tudo, o que nos cerca, afeta e consome. A contemplação permite ver nossas limitações e fragilidades (a doença, particularmente) e o seu lugar na existência. Permite mantermos vivo o sentimento de limitação e fragilidade e não irmos além dos nossos limites físicos, a não submeter nosso corpo ao que não é capaz de suportar. Essa atitude é, em última instância, fundamental para continuarmos vivos.

Considero importante trazer a experiência do perdão como uma das mais nobres e ricas experiências curativas religiosas. $\mathrm{O}$ perdão, a reconciliação e os rituais de libertação restabelecem a paz e a harmonia tanto individuais quanto comunitários. O perdão aproxima pessoas distantes. Tanto quem necessita do perdão quanto aquele que precisa oferecê-lo sofre com a distância e carrega o peso que, na medida em que o tempo passa, somente aumenta. Muitas pessoas andam curvadas e transferem para o corpo a falta do abraço, do carinho daqueles dos quais estão afastados. A palavra e o gesto de reconciliação têm um poder extraordinário. Tanto pedir perdão quanto receber o perdão é uma prática religiosa importantíssima. São gestos libertadores e permitem que a pessoa possa viver e sentir-se em paz.

Uma quarta e última prática curativa religiosa é o gesto da imposição das mãos. Essa prática tem sido estudada e é comum a várias tradições religiosas. As mãos são a nossa extensão e sua imposição no ritual religioso simboliza o poder divino que se torna concreto na vida do fiel. Fora do espaço religioso as mãos são usadas tanto para o cumprimento quanto para o abraço e são gestos de aproximação, 
de aconchego, de carinho. Sentir-se tocado é fundamental na prática curativa. Pacientes reclamam de médicos que "nem sequer os tocam". A imposição do representante divino ou da pessoa reconhecida com poderes curativos exerce a certeza do fiel não ser rejeitado, de sentir alguém próximo. O doente tocado não se sente só, sente-se amparado, protegido e isso contribui para o tratamento médico.

\section{Considerações finais e mudança de perspectiva}

A atual ênfase dada nas pesquisas envolvendo espiritualidade e saúde exige uma nova atenção das religiões e da medicina sobre esta questão. Não é mais possível pensar que estas áreas possam ficar afastadas. Por outro lado, não podemos misturar tudo, acreditando que um sincretismo de ações possa ser a solução mágica para o drama da saúde no nosso tempo. O que pretendo, neste caso, é chamar a atenção para o que chamo de "loteamento do religioso, do espiritual" na atualidade. Considero que o fato é ainda mais grave para o universo das religiões, pois as suas práticas e seu conhecimento milenar está sendo literalmente pilhado por setores que a utilizam em proveito próprio. Talvez possa ficar mais claro no exemplo do Yoga, uma prática hindu e budista, mas que, no ocidente, é utilizada por inúmeros grupos sem vínculos religiosos. Corrobora minha preocupação com o pensamento de Giovanetti (2005):

Tentar descobrir o que está no mais profundo do ser humano por meio da reflexão ou da meditação é cultivar a espiritualidade, e para desenvolver essa atitude na vida não necessito da crença em um ser superior, da religião ou da vivência da religiosidade. Daí que podemos ter uma "espiritualidade arreligiosa". A espiritualidade é independente do cultivo da religiosidade. ${ }^{8}$

Como se pode observar a partir deste pensamento e com o que se observa em práticas de outras áreas, as religiões estão perdendo um espaço importante de sua ação. Não considero que a espiritualidade seja uma ação exclusiva das religiões, mas seria uma pena que as religiões perdessem o que desenvolveram com tanto esmero e cuidado.

8 GIOVANETTI, José Paulo. Psicologia existencial e espiritualidade. In: AMATUZZI,
Mauro Martins (Org.). Psicologia e Espiritualidade. São Paulo, Paulus, 2005, p. 138. 
Um primeiro aspecto a ser considerado é quanto a uma nova postura por parte dos profissionais da medicina para com a abordagem da espiritualidade e da religiosidade na própria prática clínica. $\mathrm{O}$ DSM-IV (American Psychiatric Association, 1994) incluiu a categoria "Problemas religiosos ou espirituais", ou seja, existem problemas de ordem religiosa e espiritual que devem ser foco de tratamento terapêutico. Alguns estudos (Miovic e outros, 2006) já indicam que os clientes consideram importante que os terapeutas abordem este tema. Deve-se também observar que a própria base de crença e a história religiosa podem ser importantes para compor o universo de compreensão da pessoa e da sua construção mental. Esta construção leva-o a desenvolver práticas e relações que, dependendo dos casos, são responsáveis por sua problemática ou por seu estado atual. Eu diria que o mesmo se aplica aos profissionais da medicina.

Observa-se também uma fraca e tímida abertura dos cursos de medicina em introduzir disciplinas relativas a esta área. Como observa Moreira de Almeida (2009):

A maior parte dos profissionais da área da saúde não recebeu nenhum treinamento para lidar com essas questões, o que tem criado uma lacuna entre a prática que ainda desenvolvemos e o conhecimento existente sobre a importância da RE para a vida de nossos pacientes e de sua abordagem no contexto clínico. ${ }^{9}$

A espiritualidade não pode ser reduzida a uma terapia receitada por psicólogos ou como um tratamento adicional indicado por médicos. A espiritualidade e a oração têm sentido em si mesmas e por si mesmas, não sendo meros meios para melhorar a saúde. Para ele os médicos devem ser sensíveis e respeitosos diante das crenças, sobretudo em situações de crise, o que constitui um ingrediente indispensável para a boa prática médica. Machado da Silva e outros afirmam que

Parece cada vez mais necessário o desenvolvimento de estudos que busquem compreender a espiritualidade no contexto dos profissionais da saúde, não apenas psicólogos, uma vez que todos trabalham com seres humanos, na sua maioria em sofrimento. Neste sentido, é emergente que os profissionais valorizem e respeitem a

9 MOREIRA DE ALMEIDA, A. Espiritualidade \&Saúde Mental: O desafio de reconhecer e integrar a espiritualidade no cuidado de nossos pacientes. Zen Review, 2009, p. 2. 
espiritualidade de seus pacientes, reconhecendo seu fator protetivo, mesmo que isso não seja uma prática da sua vida pessoal. ${ }^{10}$

Quanto a este aspecto, é importante considerar o papel da religião. A religião é, acima de tudo, uma instituição e, como tal, tem uma tarefa fundamental na existência humana, como compete a todas as instituições. Todos os indivíduos necessitam encontrar e colocar as bases para a sua existência. A religião fundamenta o que chamo de "razão religiosa" para viver. Do nosso ponto de vista, a religião preenche esta busca. A religião oferece ao indivíduo o fundamento para o viver, a resposta para as questões clássicas como: "De onde viemos?", "Para onde vamos?" e "Por que estamos aqui?". Ora, considerado isso, compreendemos que o papel da religião não é um papel minoritário ou de segunda ordem. A doença da sociedade, especialmente a pós-modernidade, expõe e confirma a doença da instituição religião. Como se diz, quando uma crise atinge a religião, é porque chegamos ao ponto mais baixo desta crise e é isso, de certa forma, que se observa hoje. Torna-se necessária uma revisão dos objetivos da sociedade e, sobretudo, da religião. A doença da sociedade e das pessoas é, em última instância, a doença das suas instituições.

Outro aspecto importante a ser aprofundado é quanto ao modo de compreender e explicar o fato de muitos pacientes, embora profundamente religiosos, não obterem a tão desejada cura, mesmo utilizando-se da medicina e da religião. Este questionamento é feito por inúmeros pacientes. A presumida "falta de fé" alegada não pode ser desculpa. As religiões devem aprofundar esta reflexão e cabe também a elas a tarefa de explicar isso. Pessoas doentes ou com doenças incuráveis não são pessoas com menos fé. Essa associação automática realizada hoje reproduz um esquema antigo.

Há de se observar ainda que a religião perde um espaço fundamental que está começando a ser preenchido por, eu diria, "profissionais liberais" do sagrado e de outras áreas. Esse fenômeno é pós-moderno e atinge não somente a religião. Nesse caso, temos pessoas que se especializam em práticas outrora ligadas às religiões como a direção espiritual, os rituais de cura, as preces intercessoras, as bênçãos. O sagrado, hoje,

\footnotetext{
${ }^{10}$ MACHADO DA SILVA, L.; CAMPIO MÜLLER, M.; BRUSIUS LUDWIG, M. V.; FACCHIN, T. H. J. Psicologia positiva: espiritualidade e saúde: repercussões na psicologia contemporânea. In: BORGES TEIXEIRA, E. F.; CAMPIO MÜLLER, M. Espiritualidade e saúde, Casa do Psicólogo, Porto Alegre, 2012, p. 42.
} 
pode ser exercido por qualquer um e, pior, para isso não são necessários cursos ou diplomas. A sociedade e as religiões precisam estar atentas a isso. Nesse caso, temos muitos que exploram comercialmente práticas, especialmente as curas religiosas, com interesses econômicos.

Como última consideração, permito-me afirmar que as religiões precisam submeter as suas curas e milagres à análise médica e científica. O papa João Paulo II afirmou que a ciência pode purificar a religião do erro e da superstição, assim como a religião pode purificar a ciência da idolatria e do falso absolutismo. A maior proximidade e a abertura das religiões para a ciência e vice-versa colabora para dirimir dúvidas e malentendidos, colabora para aprofundar a fé e afastar crentes interesseiros.

\section{Referências}

AMATUZZI, M. M. (Org.). Psicologia e Espiritualidade. São Paulo: Paulus, 2005.

BARCHIFONTAINE, C. P. Espiritualidade nas Empresas. Mundo da Saúde, São Paulo, v. 31, n. 2, p. 301-305, abr.-jun. 2007.

BARTH, Wilmar Luiz. Pós-modernidade, religião e ética: da oposição à unidade. Porto Alegre: EST Editora, 2007.

BENEDETTI, L. R. Religião: crer ou consumir? Revista Vida Pastoral, ano 41, n. 257, jul.-ago. 2000.

BENEDETTI, L. R. Religião, crises e transformações. Revista Vida Pastoral, ano 50, n. 266, maio-jun. 2009.

BIANCHI, E. No nosso mundo desencantado, ensinar a fé é uma arte. Capturado em 04 jun. 2013, de <http://www.ihu.unisinos.br/noticias/520178-no-nosso-mundodesencantado-ensinar-a-fe-e-uma-arte-artigo-de-enzo-bianchi>.

BORGES TEIXEIRA, Evilázio Francisco; CAMPIO MÜLLER, Marisa; TIGRE DA SILVA, Juliana Dors (Org.). Psicologia e Qualidade de Vida. Porto Alegre: EDIPUCRS, 2004.

BORGES TEIXEIRA, Evilázio Francisco; CAMPIO MÜLLER, Marisa (Org.). Espiritualidade e saúde. São Paulo: Casa do Psicólogo, 2012.

BOTELHO, J. B. Medicina e religião: conflito de competências. Manaus: Metro Cúbico, 1991.

CATALDO NETO, Alfredo; ANTONELlO, Ivan; ITAQUI, Maria Helena (Org.). $O$ estudante de medicina e o paciente: uma aproximação à prática médica. Porto Alegre: EDIPUCRS, 2007.

CALVETTI, P. U.; CAMPIO MÜLLER, M.; TIELLET NUNES, M. L. Psicologia da Saúde e Psicologia Positiva: perspectivas e desafios. Psicologia, Ciência e Profissão, v. 4, n. 27, p. 706-717, 2007. 
CAVALCANTI, Raïssa. O retorno do sagrado. São Paulo: Cultrix, 2000.

CROSSLEY, J. P.; SALTER, D. P. A question of finding harmony: a grounded following trauma: the role of subjective experience. Journal of Affective Disorders, v. 86, p. 175$182,2005$.

DALGALARRONDO, P. Estudos sobre religião e saúde mental realizados no Brasil: histórico e perspectivas atuais. Revista de Psiquiatria Clínica, v. 34, supl. 1, 2007 , p. 25-33.

DE MARCO, M. A. (Org.). A face humana da medicina. São Paulo: Casa do Psicólogo, 2003.

FARIA, J. B.; SEIDL, E. M. F. Religiosidade e Enfrentamento em Contextos de Saúde e Doença. Revisão da Literatura. Rev. Psicologia: Reflexão e Crítica, v. 18, n. 3, p. 381-389, 2005.

FERRER, J. Medicina y Espiritualidad: redescubriendo uma antigua alianza. In: Bioética: um diálogo plural. Madrid: Ed. Univ. Pontificia Camilas, 2002. p. 891-917.

GIOVANETTI, José Paulo. Psicologia existencial e espiritualidade. In: AMATUZZI, Mauro Martins (Org.). Psicologia e espiritualidade. São Paulo, Paulus, 2005.

GUIMARÃES, H. P.; AVEZUM, Á. O impacto da espiritualidade na saúde física. Revista de Psiquiatria Clínica, v. 34, supl. 1, p. 88-94, 2007.

HELMAN, Carlos Gustavo. Cultura, saúde e doença. Porto Alegre, Artes Médicas, 1994.

INZLICHT, M.; TULLETT, A. M.; GOOD, M. The need to believe: A neuroscience account of religion as a motivated process. Religion, Brain, \& Behavior, v. 1, p. 192$212,2011$.

IRONSON, G.; SOLOMON, G.; BALBIN, E.; O'CLEIRIGH, C.; GEORGE, A.; KUMAR, M., LARSON, D., WOODS, T. E., The ironson-woods spirituality/ religiousness index is associated with long survival, health behaviors, less distress, and low cortisol in people with HIV/AIDS. Annals of Behavioral Medicine, v. 24, n. 1, p. 34-48, February 2002,

KOENIG, H. Handbook of religion and health: a century of research reviewed. Oxford: University Press, 2001.

KRIPPNER, S. Os primeiros curadores da humanidade: abordagens psicológicas e psiquiátricas sobre os xamãs e o xamanismo. Revista de Psiquiatria Clínica, v. 34, supl. 1, p. 17-24, 2007.

LUCCHETTI, G. et al. Espiritualidade na prática clínica: o que o clínico deve saber? Revista Brasileira de Clínica Medica, v. 8, n. 2, p. 154-158, 2010.

MACHADO DA SILVA, L.; CAMPIO MÜLLER, M.; BRUSIUS LUDWIG, M. V.; FACCHIN, T. H. J. Psicologia positiva: espiritualidade e saúde: repercussões na psicologia contemporânea. In: BORGES TEIXEIRA, E. F.; CAMPIO MÜLLER, M. Espiritualidade e Saúde. Porto Alegre: Casa do Psicólogo, 2012, 
MAI, C. F. M.; DENARDIN, E. S. Espiritualidade nas empresas: uma nova maneira de desenvolver líderes de sucesso. Disc. Scientia, Série: Ciências Sociais Aplicadas, Santa Maria, v. 1, n. 1, p. 19-43, 2005.

McCORD, G.; GILCHRTIRS, V.J.; GROSSMAN, S. D. Discussing spirituality with patients: a rational and ethical approach. Ann Fam Med, v. 2, n. 4, p. 356-61, 2004.

MIOVIC, M. et al. Domains of discussion in psychotherapy: what do patients really want? American Journal of Psychother, v. 60, n. 1, p. 71-86, 2006.

MOREIRA DE ALMEIDA, A. Espiritualidade \& Saúde Mental: o desafio de reconhecer e integrar a espiritualidade no cuidado com nossos pacientes. Zen Review, Esp. Saúde Mental, p. 1-6, 2009.

PERES, J. F. P.; SIMÃO, M. J. P.; NASELLO, A. G. Espiritualidade, religiosidade e psicoterapia. Revista de Psiquiatria Clínica, v. 34, supl. 1, p. 136-145, 2007.

SAAD, M., M.; MASIERO, D.; BATTISTELLA, L. R. Espiritualidade baseada em evidências. Acta Fisiátrica, v. 8, n. 3, p. 107-112, 2001.

SAAD, M.; ALMEIDA, C. I. de. Medicina Integrativa. Rev. Einstein: Educ. Contin Saúde, v. 6, n. 3, p. 135-136, 2008.

SANCHEZ, Z. S. A. A religiosidade, a espiritualidade e o consumo de drogas. Rev. Psiq. Clin., v. 34, supl. 1, p. 71-81, 2007.

SIEGEL, Bernie S. Amor, medicina e milagres. Porto Alegre: Best Seller, 1989.

SILVA NETO, N. A. Psicoterapia e Religião. Boletim Academia Paulista de Psicologia, v. XXIII, n. 3, p. 4-7, jan.-abr. 2003.

TEIXEIRA, Evilázio. Espiritualidade e técnica: as coisas que estão por detrás das coisas. Teocomunicação, v. 40, n. 3, p. 307-323, set.-dez. 2010.

TESSER, C. D.; LUZ, M. T. Uma introdução às contribuições da epistemologia contemporânea para a medicina. Rev. Ciência \& Saúde Coletiva, São Paulo, v. 7, n. 2 , p. 363-372, 2002.

VIGIL, José Maria. ¿Qué ofrece la religión a la sociedad del siglo XXI? In: Segundo Encuentro em Can Bordoi. Barcelona: CETR Editorial, 2005.

VOLCAN, S. M. A. Relationship between spiritual well-being and minor psychiatric disorders: a cross-sectional study. Saúde Pública, v. 37, n. 4, p. 440-445, 2003. 